\title{
Characteristics of Patients Presenting to the Emergency Department and Urgent Care for Treatment of Sunburn
}

\section{Citation}

Di Xia, Fan, Mary Fuhlbrigge, Michael Waul, Cara Joyce, and Arash Mostaghimi. 2017. "Characteristics of Patients Presenting to the Emergency Department and Urgent Care for Treatment of Sunburn." JAMA Dermatology (July 12). doi:10.1001/jamadermatol.2017.1874. http://dx.doi.org/10.1001/jamadermatol.2017.1874.

\section{Published Version}

doi:10.1001/jamadermatol.2017.1874

\section{Permanent link}

http://nrs.harvard.edu/urn-3:HUL.InstRepos:33786913

\section{Terms of Use}

This article was downloaded from Harvard University's DASH repository, and is made available under the terms and conditions applicable to Other Posted Material, as set forth at http:// nrs.harvard.edu/urn-3:HUL.InstRepos:dash.current.terms-of-use\#LAA

\section{Share Your Story}

The Harvard community has made this article openly available.

Please share how this access benefits you. Submit a story.

Accessibility 


\section{Trends in Nationwide Herpes Zoster Emergency Department Utilization From 2006 to 2013}

Erica D. Dommasch, MD; Cara J. Joyce, PhD; Arash Mostaghimi, MD, MPA, MPH

IMPORTANCE The effect of vaccination on emergency department (ED) utilization for herpes zoster ( $\mathrm{HZ}$ ) has not been examined to date.

OBJECTIVE To determine trends in US ED utilization and costs associated with $\mathrm{HZ}$.

DESIGN, SETTING, AND PARTICIPANTS The Nationwide Emergency Department Sample data set was examined for temporal trends in the number of visits and costs for treatment of $\mathrm{HZ}$ in EDs in the United States from January 1, 2006, through December 31, 2013. Cases of HZ were identified using validated International Classification of Diseases, Ninth Revision-Clinical Modification diagnosis codes. Patients were stratified by age: less than 20 years (varicella vaccine recommended), 20 to 59 years (no vaccine recommended), and 60 years or older ( $\mathrm{HZ}$ vaccine recommended). Population-based rates were estimated using sampling weights.

MAIN OUTCOMES AND MEASURES Population-based incidence rates of HZ-related ED visits, charge for ED services, and total charges.

RESULTS A total of 1350957 ED visits for HZ were identified between 2006 and 2013, representing $0.13 \%$ of all US ED visits. Of these patients, 563200 (51.7\%) were male; mean (SE) age was 54.0 (0.1) years. Between 2006 and 2013, the percentage of HZ-related ED visits increased from $0.13 \%$ to $0.14 \%(8.3 \%)$. This growth was driven by patients aged 20 to 59 years (increase of $22.8 \%$ [from $0.12 \%$ to $0.14 \%$ of $E D$ visits]) while the proportion of ED $H Z$ visits decreased for patients aged less than 20 years and 60 years or older, from $0.03 \%$ to $0.02 \%(-39.6 \%)$ and from $0.28 \%$ to $0.25 \%(-10.9 \%)$, respectively. For all age groups, there was an increase from 2006 to 2013 in overall adjusted total (from $\$ 92.83$ to $\$ 202.47$ million) and mean charges (from $\$ 763$ to $\$ 1262$ ) for HZ-related ED visits.

CONCLUSIONS AND RELEVANCE The number of ED visits and total cost associated with $\mathrm{HZ}$ increased between 2006 and 2013. Greater use was driven by an increased number of visits by patients aged 20 to 59 years, but populations recommended for vaccination ( $<20$ and $\geq 60$ years) demonstrated decreased ED utilization. Per-visit and total costs increased across all age groups. Vaccination may be associated with a reduction of ED utilization. Further research is required to confirm these results and examine the drivers of increased ED costs.
JAMA Dermatol. doi:10.1001/jamadermatol.2017.1546

Published online June 21, 2017. Corrected on August 2, 2017.
Supplemental content

Author Affiliations: Department of Dermatology, Beth Israel Deaconess Medical Center, Boston, Massachusetts (Dommasch); Harvard Medical School, Boston, Massachusetts (Dommasch, Mostaghimi); Department of Public Health Sciences, Loyola University, Chicago, Illinois (Joyce); Department of Dermatology, Brigham and Women's Hospital, Boston, Massachusetts (Mostaghimi).

Corresponding Author: Arash Mostaghimi, MD, MPA, MPH, Department of Dermatology, Brigham and Women's Hospital, 15 Francis St, PBB-B 421, Boston, MA O2115 (amostaghimi@bwh.harvard .edu). 
$\mathrm{H}$ erpes zoster (HZ), or shingles, is caused by reactivation of the HZ virus, the same virus that causes varicella. ${ }^{1}$ One-third of individuals in the United States will develop HZ in their lifetime, with the risk increasing sharply after age 50 years. ${ }^{2}$ Any individual who has had varicella or received the varicella vaccine can develop $\mathrm{HZ}$, although the risk is lower in those who are vaccinated. ${ }^{3}$

The rate of HZ has been increasing gradually over many years in the United States and other countries. The reason for this trend is currently unknown. ${ }^{4-6}$ According to a hypothesis proposed by Hope-Simpson, exposure to primary varicella or subclinical latent varicella zoster virus can boost varicella zoster virus-specific immunity and reduce the risk of $\mathrm{HZ}^{7}{ }^{7} \mathrm{~A}$ liveattenuated vaccine for varicella was introduced into the US vaccination schedule in 1995 for children aged 12 months or older, with subsequent significant declines in the incidence of varicella. Although vaccination rates were slow at first, they reached 89\% in 2006 in children aged 19 to 35 months. ${ }^{8}$ Observational studies suggest that individuals vaccinated for varicella are at a decreased risk of developing HZ. ${ }^{3}$ However, studies examining the effect on the overall population rates in the United States with observation periods ranging from 1992 through 2010 have been inconclusive..$^{3-6,9}$

A live-attenuated vaccine for $\mathrm{HZ}$ has been available in the United States since 2006. The vaccine reduces the likelihood of developing HZ by $51.3 \%$ in individuals aged 60 years or older, and vaccinated individuals who develop HZ usually have less severe disease. In 2008, the Advisory Committee on Immunization Practices (ACIP) recommended zoster vaccine live for the prevention of $\mathrm{HZ}$ and its complications among adults aged 60 years or older. ${ }^{2}$ Vaccination rates in this population increased from $6.7 \%$ in 2008 to $24.2 \%$ in $2013 .{ }^{10,11}$

To our knowledge, there are no data on nationwide emergency department (ED) utilization, hospitalization, and costs related to $\mathrm{HZ}$ and limited data on trends of disease since routine varicella vaccination was implemented in 1995 for children, as well as both before and after the ACIP recommendation of $\mathrm{HZ}$ vaccination in 2008. We hypothesized that, despite the increased incidence of $\mathrm{HZ}$, the introduction of the $\mathrm{HZ}$ vaccine in 2008 led to attenuation of severe disease and reduction of ED utilization for patients aged 60 years or older with HZ. We additionally hypothesized that routine varicella vaccination decreased ED utilization for HZ in patients aged less than 20 years.

In this study, we used the Nationwide Emergency Department Sample (NEDS) to evaluate trends in ED utilization and costs to assess the potential impact of routine varicella vaccination and $\mathrm{HZ}$ vaccination.

\section{Methods}

\section{Data Source}

We conducted a US population-based, descriptive epidemiologic study of HZ-related ED visits from 2006 through 2013 using the NEDS, a nationally representative all-payer database that includes a $20 \%$ stratified sample of US community hospitals and contains data on approximately 130 million ED

\section{Key Points}

Question What is the effect of vaccination on emergency department utilization for herpes zoster?

Findings In this population-based, descriptive epidemiologic study of more than 1.3 million herpes zoster-related emergency department visits from 2006 through 2013, the overall rate of visits rose by $8.3 \%$, driven by an increased number of visits by patients aged 20 to 59 years; populations recommended for vaccination (aged $<20$ and $\geq 60$ years) demonstrated a decrease in utilization. Herpes zoster annual incidence rates fell after the recommended use of the herpes zoster vaccine in 2008 in patients 60 years or older.

Meaning Vaccination may be associated with a reduction of emergency department utilization for herpes zoster.

visits per year when weighted. ${ }^{12}$ Cases of $\mathrm{HZ}$ were identified by a primary International Classification of Diseases, Ninth Revision-Clinical Modification (ICD-9-CM) code of 053.x, which has been shown to detect HZ with $98 \%$ sensitivity and a positive predictive value between $85 \%$ and $100 \% .{ }^{13-15}$ The Partners Healthcare Institutional Review Board approved the study and granted an exemption for use of deidentified data from the NEDS database.

\section{Statistical Analysis}

We estimated the number of population-based total and HZrelated ED visits using sampling weights, clusters, and strata provided in the NEDS databases for each year. We stratified patients into the following age groups: less than 20 years, 20 to 59 years, and 60 years or older. Population-based incidence rates were calculated using US Census Bureau American FactFinder. ${ }^{16}$ Emergency department charges were adjusted to 2016 dollars using the Consumer Price Index adjustments for medical care. ${ }^{17}$ Separate logistic regression models for each age group were used to estimate the change in the log odds of a HZ visit per 1-year increase in the survey, and significant coefficients were interpreted as a trend in the probability of an HZ visit over the survey time period. We used the Rao-Scott $\mathrm{X}^{2}$ test to compare the proportion of visits for HZ from 20062007 with those from 2008-2013 among patients 60 years or older. $P$ values $<.05$ were considered statistically significant. All tests were 2-tailed except for the Rao-Scott $\chi^{2}$ test, which is 1-tailed. All group comparisons were unpaired. Analyses were performed with survey procedures in SAS, version 9.4 (SAS Institute Inc).

\section{Results}

From 2006 to 2013, there were 1350957 visits to the ED for $\mathrm{HZ}$, which represented $0.13 \%$ of all ED visits in the United States (Table 1). When stratified by age groups, visits by patients 60 years or older represented $42.3 \%$ of all ED visits for HZ compared with representing $21.3 \%$ of ED visits without a primary diagnosis of HZ. Most patients were women (58.3\%) and there was a slightly higher number of visits for $\mathrm{HZ}$ in the summer 


\begin{tabular}{|c|c|c|}
\hline \multirow[b]{2}{*}{ Characteristic } & \multicolumn{2}{|l|}{ No. $(\%)^{\mathrm{a}}$} \\
\hline & $\begin{array}{l}\text { Visits With Primary } \\
\text { Diagnosis of HZ }\end{array}$ & $\begin{array}{l}\text { Visits Without Primary } \\
\text { Diagnosis of } \mathrm{HZ} \\
\end{array}$ \\
\hline Total visits & $1350957(0.13)$ & 1024131999 (99.87) \\
\hline Age, mean (SE), y & $54.0(0.1)$ & $38.5(0.2)$ \\
\hline \multicolumn{3}{|l|}{ Age group, y } \\
\hline$<20$ & 66078 (4.9) & 247892699 (24.2) \\
\hline $20-59$ & $713753(52.8)$ & $557985576(54.5)$ \\
\hline$\geq 60$ & $571115(42.3)$ & $218246765(21.3)$ \\
\hline \multicolumn{3}{|l|}{ Sex } \\
\hline Male & 563200 (41.7) & $459670847(44.9)$ \\
\hline Female & 787495 (58.3) & $564190324(55.1)$ \\
\hline \multicolumn{3}{|l|}{ Hospital region } \\
\hline Northeast & 279676 (20.7) & $197994358(19.3)$ \\
\hline Midwest & $296883(22.0)$ & $238684851(23.3)$ \\
\hline South & $524783(38.8)$ & $403661728(39.4)$ \\
\hline West & $249616(18.5)$ & $183791061(17.9)$ \\
\hline \multicolumn{3}{|l|}{ Primary payer } \\
\hline Medicare & 479771 (35.6) & $214329554(21.0)$ \\
\hline Medicaid & $179478(13.3)$ & $256676982(25.1)$ \\
\hline Private insurance & $393090(29.2)$ & $322453842(31.6)$ \\
\hline Self-pay & $239811(17.8)$ & $169336307(16.6)$ \\
\hline No charge & $12255(0.9)$ & $7878378(0.8)$ \\
\hline Other & $42411(3.1)$ & 49999330 (4.9) \\
\hline \multicolumn{3}{|l|}{ Month of visit by quarter } \\
\hline December-February & $259796(23.0)$ & 214160934 (24.5) \\
\hline March-May & $278900(24.7)$ & $221966293(25.4)$ \\
\hline June-August & $304703(27.0)$ & $222131582(25.4)$ \\
\hline September-November & $284003(25.2)$ & $216418879(24.7)$ \\
\hline \multicolumn{3}{|l|}{ Range in days of visit } \\
\hline Monday-Friday & 861779 (63.9) & $729065973(71.2)$ \\
\hline Saturday-Sunday & $486917(36.1)$ & $294554910(28.8)$ \\
\hline $\begin{array}{l}\text { Charge for ED services, } \\
\text { mean (SE), } \$ \$\end{array}$ & $1035(14)$ & $2321(29)$ \\
\hline \multicolumn{3}{|l|}{ ED disposition } \\
\hline Routine & 1229972 (91.0) & $816794125(79.8)$ \\
\hline $\begin{array}{l}\text { Transfer to short-term } \\
\text { hospital }\end{array}$ & $3626(0.3)$ & $14230986(1.4)$ \\
\hline Other transfers ${ }^{c}$ & $5341(0.4)$ & $11848345(1.2)$ \\
\hline Home health care & $1952(0.1)$ & $1978365(0.2)$ \\
\hline Against medical advice & $2712(0.2)$ & 14012246 (1.4) \\
\hline Admitted as inpatient & $97618(7.2)$ & $154155613(15.1)$ \\
\hline Died in ED & $33(0)$ & $1544204(0.2)$ \\
\hline $\begin{array}{l}\text { Not admitted; } \\
\text { destination unknown }\end{array}$ & $13(0)$ & $19441(0)$ \\
\hline \multicolumn{3}{|l|}{ Inpatient characteristics } \\
\hline $\begin{array}{l}\text { Length of stay, } \\
\text { mean (SE), d }\end{array}$ & $4.72(0.04)$ & $4.87(0.02)$ \\
\hline $\begin{array}{l}\text { Charge for ED and inpatient } \\
\text { services, mean (SE), \$ }\end{array}$ & $30056(561)$ & $40400(521)$ \\
\hline
\end{tabular}

Abbreviations: $\mathrm{ED}$, emergency department; $\mathrm{HZ}$, herpes zoster.

a Subcategories of counts may not sum to totals owing to missing values for some variables. Percentages were calculated using the total counts for each subcategory.

${ }^{\mathrm{b}}$ All charges adjusted to 2016 dollars.

' Skilled nursing facility, intermediate care, and other.
Figure 1. Percentage of Total Emergency Department (ED) Visits With Primary Diagnosis of Herpes Zoster (HZ) From 2006 to 2013

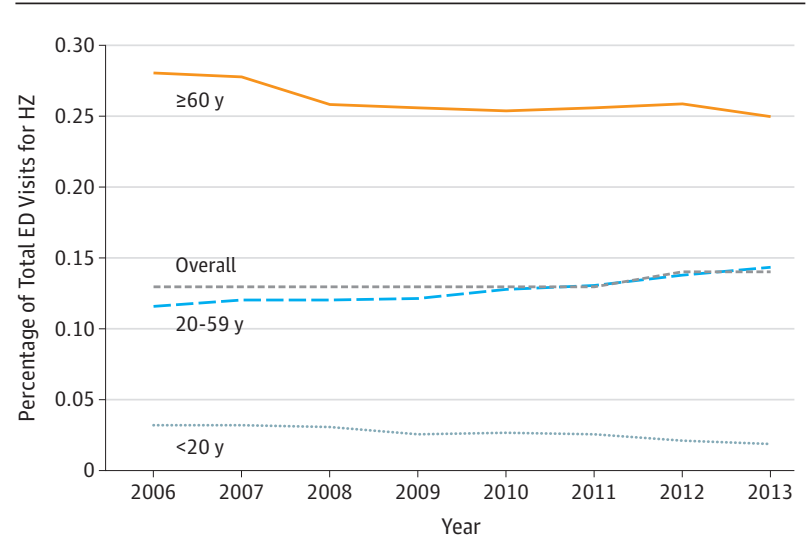

Percentages were calculated as weighted number of ED visits with primary diagnosis of $\mathrm{HZ}$ over the total number of ED visits, multiplied by 100 .

months (June through August). Overall, 7.2\% of patients who presented to the ED with a primary diagnosis of HZ were admitted, with a mean (SE) length of stay of 4.72 (0.04) days (Table 1). The percentage of patients admitted declined from 2006 to 2013 for all age groups. We found that the overall percentage of HZ-related ED visits (Figure 1), population-based incidence rates (eTable in the Supplement), percentage admitted, and mean ED and inpatient charges, rose with increasing age (Table 2).

From 2006 to 2013, the overall population-based rate for HZ-related ED visits increased from 51.57 to 59.44 per 100000 persons per year (15.2\%). The overall percentage of HZrelated ED visits also increased from $0.13 \%$ to $0.14 \%$ (8.3\%). After stratifying the sample into age groups $(<20,20-59$, and $\geq 60$ years), the percentage of ED HZ visits from 2006 to 2013 increased for patients 20 to 59 years from $0.12 \%$ to $0.14 \%$ (22.8\%) (Figure 1). The percentage of ED HZ visits decreased for the $<20$ years and 60 years or older groups, from $0.03 \%$ to $0.02 \%(-39.6 \%)$ and from $0.28 \%$ to $0.25 \%(-10.9 \%)$, respectively $(P<.001$ for the change in odds of an $\mathrm{HZ}$ visit by year for all age groups).

For all age groups, there was an increase from 2006 to 2013 in overall adjusted total (from $\$ 92.83$ to $\$ 202.47$ million) and mean charges (from $\$ 763$ to $\$ 1262$ ) for HZ-related ED visits (Figure 2 and Figure 3). For patients 60 years or older, although incidence rates declined, total charges increased by $110 \%$. This rise was due to an increase in that population, as well as a greater mean charge per visit. Adjusted mean charges per HZ-related ED visit increased the most for patients 60 years or older (75.5\%) from 2006 to 2013 compared with those 20 to 59 years (57.3\%) and less than 20 years (58.6\%) (Figure 3$)$. The increases in adjusted mean charges per ED visit for HZ outpaced those seen for all ED visits for any indication for patients 60 years or older and those less than 20 years, which increased by $72.8 \%$ and $45.9 \%$, respectively, but were similar for the 20- to 59 -year age group (59.5\%). 


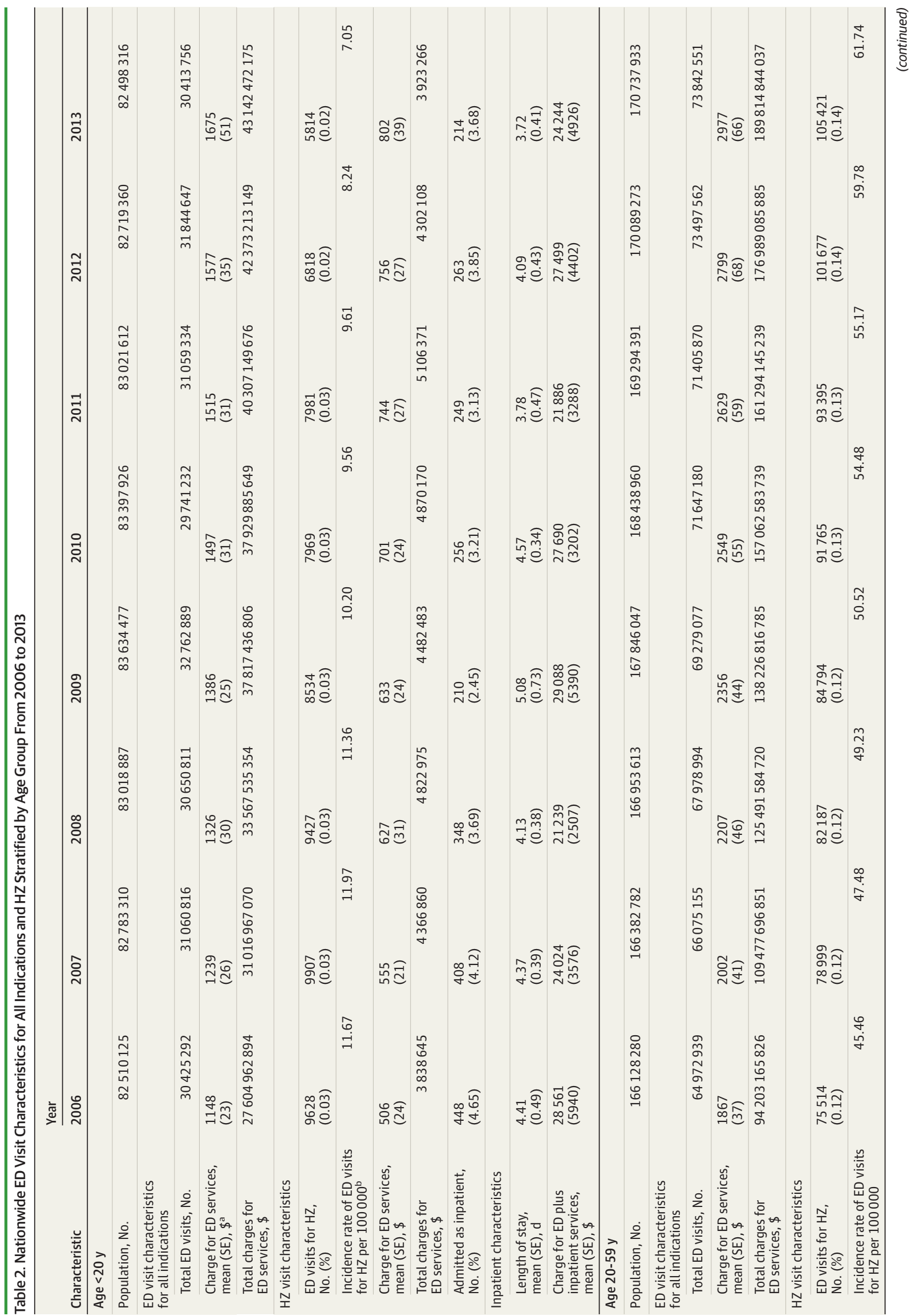




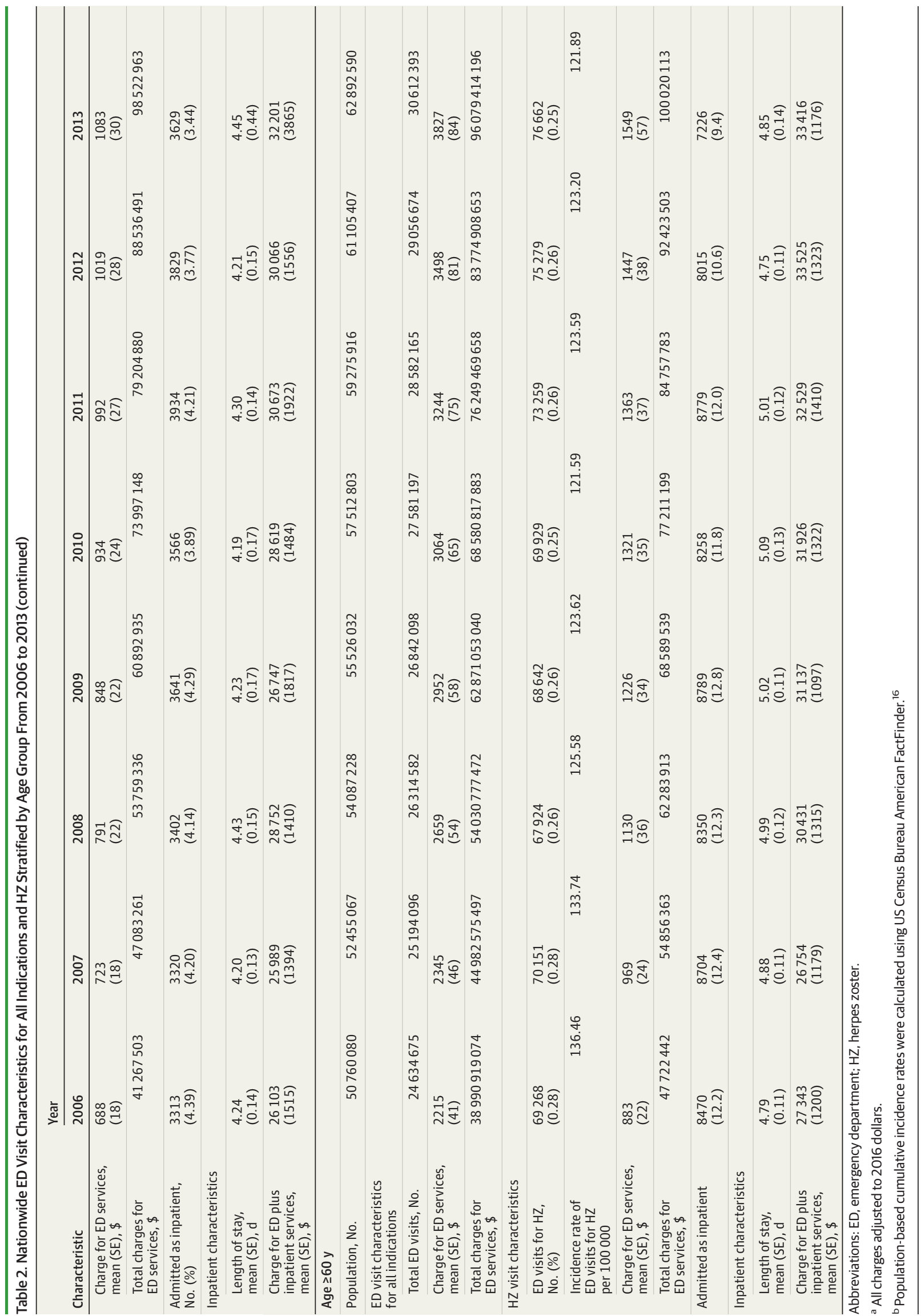


Figure 2. Percentage of Total Emergency Department (ED) Visits With Primary Diagnosis of Herpes Zoster (HZ) and Associated Annual Charge for ED Services From 2006 to 2013

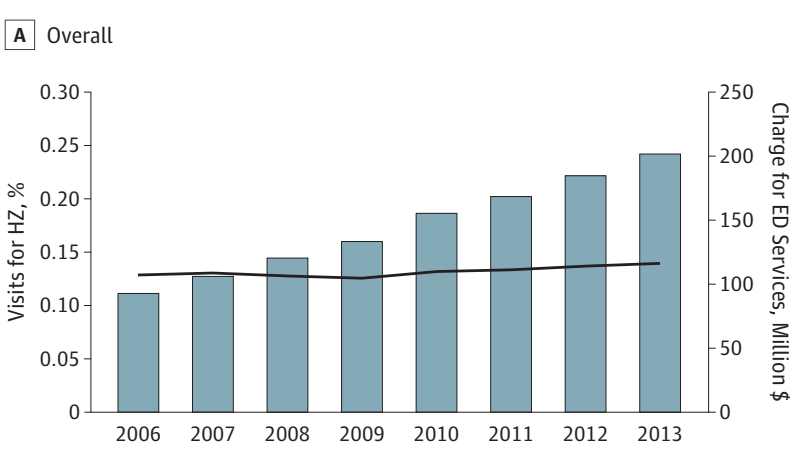

C Age 20-59 years

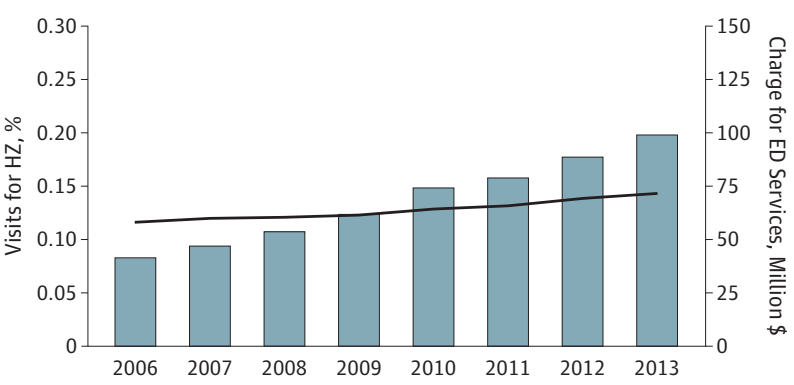

B Age $<20$ years

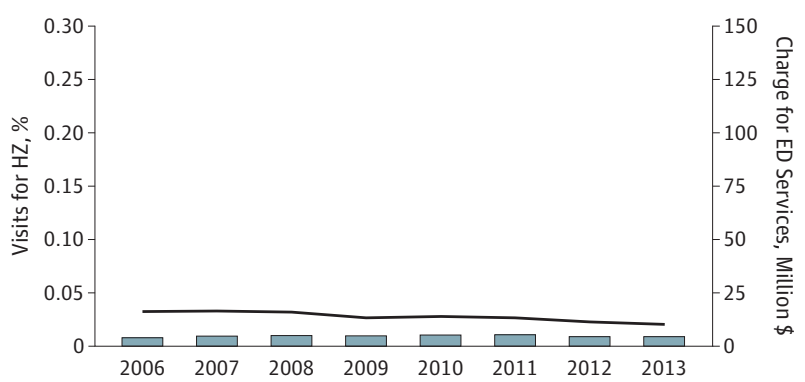

D Age $\geq 60$ years

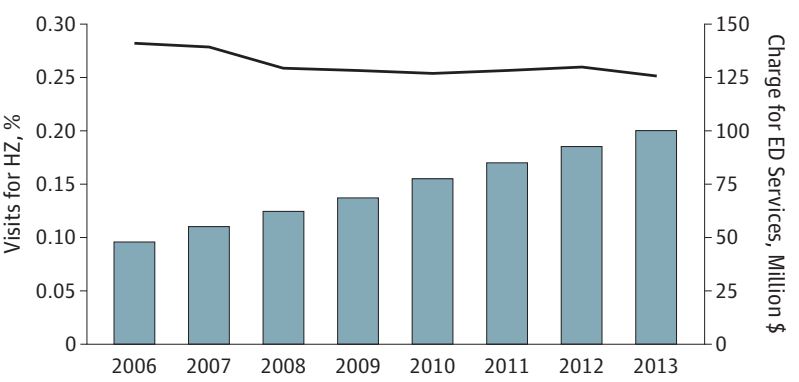

Proportion of ED visits for $\mathrm{HZ}$ and charge for HZ-related ED services from 2006 to 2013 overall (A), in patients aged less than 20 years (B), 20 to 59 years (C), and 60 years or older (D). All charges were adjusted to 2016 dollars using the Consumer Price Index adjustments for medical care.

Figure 3. Mean Charge per Emergency Department (ED) Visit for Herpes Zoster in 2006 and 2013

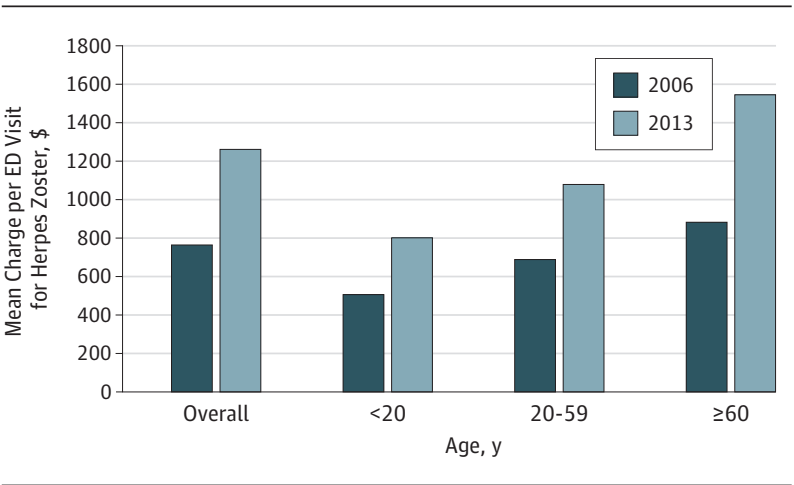

All charges were adjusted to 2016 dollars using the Consumer Price Index adjustments for medical care.

\section{Discussion}

We identified increasing utilization and costs associated with treatment of HZ in US EDs. Although the overall proportion of ED visits for $\mathrm{HZ}$ is increasing marginally $(0.13 \%$ to $0.14 \%$ from 2006 to 2013), stratification by age revealed that this growth is driven by patients between ages 20 and 59 years, while younger and older patients have had fewer ED visits for HZ over time. We found that a higher percentage of women presented to the ED with HZ (58.3\%), which is consistent with the results of almost all studies identifying a greater disease burden among women. ${ }^{2}$ However, women were also higher utilizers of the ED for any indication (Table 1).

The trends in ED utilization may reflect a combination of influences. Patients seen in the ED for HZ must (1) develop $\mathrm{HZ}$ and (2) choose the ED as their venue of care. The trends that we observed thus could be attributable to trends in the incidence of HZ and/or ED utilization among different age groups. We found that, although the overall incidence rate of ED visits for all indications for patients 60 years or older and those less than 20 years remained stable from 2006 to 2013, there was a decrease in the rate of ED visits for HZ for these age groups. This finding suggests that the observed decrease may be due to a reduced disease incidence among individuals vaccinated for varicella ( $<20$ years) and those who qualify for $\mathrm{HZ}$ vaccination ( $\geq 60$ years), potentially providing further insight into the population-level impact of vaccination.

Although we found a significant difference in the proportion of ED visits related to HZ before and after the recommended use of the HZ vaccine in $2008(P<.001)$ in the 60 years or older age group, we were unable to perform a similar analysis examining the effect of the varicella vaccination (which was introduced into the vaccination schedule in 1995) on HZ incidence in the younger than 20-year age group since the NEDS database started in 2006. Thus, the decline seen in this population could have been associated with other factors. However, the decrease in $\mathrm{HZ}$ incidence in patients aged less than 
20 years is consistent with prior studies in the outpatient setting that found a stabilization or decrease in age-specific incidence of HZ in the varicella-vaccinated population before and after 1996. ${ }^{4,5}$ Among patients aged 20 to 59 years, there was an increase in the rate of HZ-related ED visits from 2006 to 2013, which may have been partially due to an elevated rate of ED visits for all indications in this age group. However, HZrelated ED visits represented an increasing percentage of all ED visits over this time period, which suggests a rising disease incidence in this age group.

Other studies have found an increasing incidence of $\mathrm{HZ}$ in the United States and other countries, consistent with our findings. ${ }^{2,18-21}$ The cause for this elevation in disease burden is unclear and is likely multifactorial. The age-specific increased rate of HZ-related ED visits in patients aged 20 to 59 years may be explained in part by the Hope-Simpson hypothesis that increased varicella zoster virus vaccination has led to a rise in overall HZ incidence. ${ }^{7}$ However, other studies have found that the rate of $\mathrm{HZ}$ was rising before introduction of routine varicella zoster virus vaccination and that this increased rate did not accelerate after routine vaccination was started. ${ }^{19}$ Unfortunately, the NEDS data collection began in 2006 and we could not examine prior trends.

The substantial increase in costs is also likely to be multifactorial. The NEDS database does not provide insight into the treatments administered at each visit, and it is unclear whether changes in practice (additional testing or imaging) or increased costs for similar therapeutics are the culprit.

These findings suggest that, although vaccination rates may be correlated with a broader effect on $\mathrm{HZ}$ incidence and downstream utilization of ED services, reduction in disease incidence or ED presentation may be insufficient to reduce overall health care expense. Further research is needed to identify drivers of increased costs and implement interventions to streamline treatment and evaluation of patients with HZ. Currently, there is a subunit vaccine containing varicella zoster virus glycoprotein $\mathrm{E}$ and the ASO1B adjuvant system (called HZ/ su) being evaluated for the prevention of HZ. Because it is not a live vaccine, the HZ subunit vaccine is considered safe for individuals who are immunocompromised and has been found to have an efficacy rate of $97.2 \%$ in adults 50 years or older in a phase 3 trial. This vaccine may provide a means by which we can reverse the disease burden and associated costs of $\mathrm{HZ}$ in this population. ${ }^{22}$

\section{Limitations}

These results must be interpreted in the context of our study design. Although we present these changes in ED utilization over a period marked by the introduction of vaccines, this study does not allow us to directly link change in utilization to vaccination. This limitation is especially true in the context of the substantial change in the American health care system that occurred during the study period-the real driver of changes in ED presentation and cost may be larger systems issues. Aside from primary payer type, there are no indicators of changing access to care or health care coverage, and we were not able to adjust for this in our analysis.

Although the NEDS database provides nationally representative estimates for ED utilization, there are limitations to these data. Because this is a publicly available, deidentified data set, validation by medical records review of $\mathrm{HZ}$ cases identified by ICD-9-CM codes was not possible. However, prior studies have found that the algorithm used in the present study detected HZ with a positive predictive value of $85 \%$ or more. ${ }^{13-15}$ In addition, because our study was limited to ED visits, the results may not be generalizable to the outpatient setting.

Our findings should be corroborated in other data sets, especially those including outpatient visits for $\mathrm{HZ}$, that allow for evaluation of the impact of patient characteristics and validation of our findings in other settings outside of the ED.

\section{Conclusions}

Our study found an increase in total ED visits associated with HZ between 2006 and 2013 due to an increased number of visits by patients aged 20 to 59 years. Despite decreased utilization in patients aged less than 20 years and 60 years or older, we found increased total adjusted charges in these populations. Our findings suggest that vaccination may be associated with a reduction of ED utilization. Further research is necessary to identify the drivers of increased costs.

\section{ARTICLE INFORMATION}

Accepted for Publication: April 6, 2017.

Published Online: June 21, 2017. doi:10.1001/jamadermatol.2017.1546

Correction: This article was corrected on August 2 , 2017, to fix an age range error repeated in the Abstract, Key Points, Introduction, and caption to Figure 2.

Author Contributions: Drs Joyce and Mostaghimi had full access to all of the data in the study and take responsibility for the integrity of the data and the accuracy of the data analysis.

Study concept and design: Dommasch, Mostaghimi. Acquisition, analysis, or interpretation of data: All authors.

Drafting of the manuscript: All authors. Critical revision of the manuscript for important intellectual content: All authors.
Statistical analysis: All authors. Administrative, technical, or material support: Mostaghimi.

Supervision: Dommasch, Mostaghimi.

Conflict of Interest Disclosures: None reported.

\section{REFERENCES}

1. Yawn BP, Saddier P, Wollan PC, St Sauver JL, Kurland MJ, Sy LS. A population-based study of the incidence and complication rates of herpes zoster before zoster vaccine introduction. Mayo Clin Proc. 2007;82(11):1341-1349.

2. Harpaz R, Ortega-Sanchez IR, Seward JF; Advisory Committee on Immunization Practices (ACIP) Centers for Disease Control and Prevention (CDC). Prevention of herpes zoster: recommendations of the Advisory Committee on
Immunization Practices (ACIP). MMWR Recomm Rep. 2008;57(RR-5):1-30.

3. Weinmann S, Chun C, Schmid DS, et al. Incidence and clinical characteristics of herpes zoster among children in the varicella vaccine era, 2005-2009. $J$ Infect Dis. 2013;208(11):1859-1868.

4. Jumaan AO, Yu O, Jackson LA, Bohlke K, Galil K Seward JF. Incidence of herpes zoster, before and after varicella-vaccination-associated decreases in the incidence of varicella, 1992-2002. J Infect Dis. 2005;191(12):2002-2007.

5. Leung J, Harpaz R, Molinari NA, Jumaan A, Zhou F. Herpes zoster incidence among insured persons in the United States, 1993-2006: evaluation of impact of varicella vaccination. Clin Infect Dis. 2011;52(3):332-340.

6. Yih WK, Brooks DR, Lett SM, et al. The incidence of varicella and herpes zoster in Massachusetts as 
measured by the Behavioral Risk Factor Surveillance System (BRFSS) during a period of increasing varicella vaccine coverage, 1998-2003. BMC Public Health. 2005;5:68.

7. Guzzetta G, Poletti P, Del Fava E, et al. Hope-Simpson's progressive immunity hypothesis as a possible explanation for herpes zoster incidence data. Am J Epidemiol. 2013;177(10): 1134-1142.

8. Centers for Disease Control and Prevention. National Immunization Survey (NIS). NIS table data for 2006. http://www.cdc.gov/vaccines/imz -managers/coverage/nis/child/data/tables-2006 html. Accessed June 27, 2016.

9. Hales CM, Harpaz R, Joesoef MR, Bialek SR. Examination of links between herpes zoster incidence and childhood varicella vaccination. Ann Intern Med. 2013;159(11):739-745.

10. Williams WW, Lu PJ, O'Halloran A, et al; Centers for Disease Control and Prevention (CDC). Vaccination coverage among adults, excluding influenza vaccination-United States, 2013. MMWR Morb Mortal Wkly Rep. 2015;64(4):95-102.
11. Greby SM, Lu PJ, Euler G, Williams WW, Singleton JA. NHIS 2009 Adult Vaccination Coverage. 2010; http://www.cdc.gov/vaccines/imz -managers/coverage/nhis/2009-nhis.html. Accessed June 26, 2016.

12. NEDS Overview. Healthcare Cost and Utilization Project (HCUP). December 2014 http://www.hcup-us.ahrq.gov/nedsoverview.jsp. Accessed July 23, 2015.

13. Donahue JG, Choo PW, Manson JE, Platt R. The incidence of herpes zoster. Arch Intern Med. 1995;155(15):1605-1609.

14. Klompas M, Kulldorff M, Vilk Y, Bialek SR Harpaz R. Herpes zoster and postherpetic neuralgia surveillance using structured electronic data. Mayo Clin Proc. 2011;86(12):1146-1153.

15. Yawn BP, Wollan P, St Sauver J. Comparing shingles incidence and complication rates from medical record review and administrative database estimates: how close are they? Am J Epidemiol. 2011;174(9):1054-1061.

16. United States Census Bureau. American FactFinder. http://factfinder2.census.gov. Accessed December 10, 2015
17. United States Department of Labor. CPI Detailed Report. Data for March 2016; Table 25C. http://www.bls.gov/cpi/cpid1603.pdf. Accessed May 1, 2016.

18. Jardine A, Conaty SJ, Vally H. Herpes zoster in Australia: evidence of increase in incidence in adults attributable to varicella immunization? Epidemiol Infect. 2011;139(5):658-665.

19. Kawai K, Yawn BP, Wollan P, Harpaz R. Increasing incidence of herpes zoster over a 60-year period from a population-based study. Clin Infect Dis. 2016;63(2):221-226.

20. Russell ML, Dover DC, Simmonds KA, Svenson LW. Shingles in Alberta: before and after publicly funded varicella vaccination. Vaccine. 2014; 32(47):6319-6324.

21. Wu PY, Wu HD, Chou TC, Sung FC. Varicella vaccination alters the chronological trends of herpes zoster and varicella. PLoS One. 2013;8(10): e77709.

22. Lal H, Cunningham $A L$, Godeaux $O$, et al; ZOE-50 Study Group. Efficacy of an adjuvanted herpes zoster subunit vaccine in older adults. $N$ Engl J Med. 2015;372(22):2087-2096. 